\title{
Development of Shoe Theft Detection and Prevention System
}

\author{
Hee_Ae Kim ${ }^{1}$, Seong-Yoon Shin ${ }^{2 *}$, Yang-Won Rhee ${ }^{2}$, Kwang-Seong Shin $^{3}$ and \\ Jong_Chan Lee ${ }^{2}$ \\ ${ }^{1}$ Undergraduate, Department of Computer Information Engineering, Kunsan National \\ University, Kunsan, 573-701, Korea \\ ${ }^{2}$ Propfessor, Department of Computer Information Engineering, Kunsan National \\ University, Kunsan, 573-701, Korea \\ ${ }^{3}$ General Manager, SonIT, 1-505, Ace Twin Tower, 212-4, Kuro-Dong Kuro-Ku, \\ Seoul, 152-053, Korea \\ \{heeae_kim,s3397220,ywrhee, chan2000\}@kunsan.ac.kr,waver@sonit.com

\section{Abstract}

The objectives of this research are to assess a shoe theff detection and prevention system. The theft of shoes can happen relatively frequently in Korean or Japanese societies because people often have to take off their shoeswhen entering and eating at a local restaurant or any other type of crowded building struc@re. A singlepair of shoes can cost hundreds of dollars; hence, the theft of shoes can burt people financially. This research adopts difference image comparison, with use of binary images, pixel rates, time, and a histogram that uses Bhattacharyya distance measurements. Nnaddition, we assess the originality and quality of our research and evaluate through video forensics studies. We hope that this research will become the catalyst for society to 'grow morally. The social climate of today's society is becoming ever more fyaught, but we have to endeavor to change this by introducing more positivity. A central tenet of a healthy society is the rule of law and respect for property rights.

Keywords: shoe theft detection, difference image, bhattacharyya distance, pixel rates, video forensics

\section{Introduction}

Shoe theft Is one of the most common incidents that we can confront on a daily basis. It can happen regardless of time or place; the important thing is that we first take off our shoes. As sueh, it most often occurs at crowded venues, such as restaurants, shower facilities and schools. Picture the scene: a man is looking to leave after having a really pleasant conversation with his friends. Yet, to leave he must first find his shoes. Put the price of his shoes to one side for a moment. Without his shoes he may face the uncomfortable and embarrassing situation of having to delay his coworkers and friends, who are. in all likelihood, already at the exit, waiting for him. It is likely he would vent his anger at the owner of the establishment. However, the owner had probably already made sure to hang a waiver on the wall that reads: "Please store your shoes in our shoes rack. If you have valuables, bring them to our casher for temporary storage at our safe. We will not hold any responsibility for the loss of your shoes."

\footnotetext{
${ }^{*}$ Corresponding Author
} 
However the venue owner is not completely free from legal responsibility. Article 152 of the Liability of Hospitality Business Operators, of Commercial Act of the Republic of Korea states the following:

(1) Unless a hospitality business operator can prove that he/she has not been negligent in providing due care in the custody of articles deposited from his/her guests to him/her or his/her employee, the hospitality business operator shall be liable for the damages resulting from the loss of, or damage to, the articles kept in his/her custody.

(2) A hospitality business operator shall be liable for the loss of or damage to portable goods brought into his/her establishments, even if not particularly deposited by the guest, when it is due to the lack of due care of the business operator or any of his/her employees.

(3) No hospitality business operator shall be exonerated from liability under paragraphs (1) and (2), even if he/she has provided due notice that he/she is not liable/or the loss of or damage to the portable goods of guests.

As stated above, venue owners are not exempt from legal responsibility. However, there are some people who seek to exploit Article 152 bycompelling owners to provide compensation for fabricated losses. Venue owners are thus force to pay more attention to ways to reduce the risk of being cheated and of shoe theft occurring. Moreover, shoppers and restaurant goers should pay more attenfion to stope their shoes in a safe place.

The second chapter of this thesis wiil discuss insights gleamed from the wider literature on this subject. Our suggested shoe theft prevention system will be discussed in third chapter. In Chapter 4, we will show how we implemented our system and the results are discussed, and conclusions given, in Çapter 5 .

\section{Related Works}

The field of video image forensics is relative new within image forensics studies. There have been several studies of digital image forensic markings using D/A and A/D conversion, such as the print-to-capture model performed by a printer and digital camera [1]. There has likewise been research of a similar file detection system to aid digital forensic investigation [2].

Furthermore, there has been a study to operate a cross-layer program suitable for students of computer lechnology and law departments to help them learn multi-disciplinary convergenca subjects [3].

Image change detection studies typically rely on use of the histogram comparison method. Tonomura et al.[4-6] suggest a simple method that uses a gray level histogram comparison technique to extract the edge of an image using threshold values as reference points.

Ueda et al. [7] use the change rate of a color histogram to detect the edge of an image. Nagasaka et al. [6] apply several simple statistical comparison methods for both a gray level histogram and color histogram.

Zhang et al. [4] prove the efficacy of the histogram comparison method in terms of accuracy and processing speed by examining pixel difference, statistical data difference, and several histogram methods.

Nagasaka et al. [6] suggest a chi-squared examination algorithm that, though simple, is effective. This method not only emphases the difference between two different frames, but also the movements of the camera and objects. Nonetheless, the overall performance of this 
Nagasaka-Tanaka method (chi-squared examination algorithm) is inferior to that of the linear histogram comparison method suggested by Tonomura et al. [5], with more computation required.

Recent studies include multi-histogram based scene change detection for frame rate-up conversion method [8], a scene change detection algorithm [10] that uses the relationship between all video frames and reference frames (i.e., the relationship between adjoining frames).

There is a study of adaptive parallax control based on 3D scene change detection method for stereoscopic video sequences [11], and a new method that uses the statistical characteristics of optical flow in order to find the most well presented video frame for effective scene change detection [12].

\section{Shoe Theft Detection System}

The shoe theft detection system examined in this study uses a surveikance video camera system to prevent shoe theft or the risk of taking another person's shoes. The system is capable of sounding an alarm or displaying a warding sign in the eyent that a person takes another person's shoes instead of his/her own. The following is the overall procedure of the shoe theft detection system examined in this study.

(1) It stores the first scene of a video when the program is started in order to use it to generate a difference image.

2) It changes the difference image into binary code.

(3) It can run in two different modes person's present and no person.

(4) This system ackmowledges that a person or people are present on the scene if the number of white pixeis over the number of black pixels on the entire screen exceeds a pre-assigned value.

(5) It detects shoes when the mode is changed from no person mode to person present mode and it sayes the pre-recorded time and the image of the detected shoes. Here, the image of detected shoes is defined as the image of shoes that have been detected while no person showed up. After completing this process, it records two different time points: one for the time of a person's action of placing his/her shoes on 2 shoe rack, and the other for the time at which the person passed by the shoe rack.

(6) While a person is present on the scene, it temporarily selects and saves a binary image that has highest white pixel ratio, assuming this image is the most suitable image of the scene with a person present.

(7) It saves the pre-recorded time and the image of detected shoes 2 seconds later when the mode is switched from person present mode to no person mode. If a person stored his/her shoes later than 2 seconds, meaning the person takes more than 2 seconds to put his/her shoes on the shoe rack, it skips the shoe recording process shown in (5). 
(8) So long as no person shows up, the system continues to detect shoes, but not store data.

(9) If new shoes are detected while searching for detected shoes, it temporarily saves a person's image.

(10) If the operator tries to find shoes that have been detected, but the shoes have gone, it searches for the time of the shoes being brought in from person data, compares the histograms of the images of the people who brought in shoes at that time and the histograms of the images of people who took shoes out by using Bhattacharyya distance algorithm in order to find whether two images are similar or not. If the results of the comparison shows a preset level of similarity or higher, 1freturns the result that the legitimate owner took the shoes and does not take any further action, but if the similarity level is lower than the pre-assigned level, it returns the result that a theft has taken place and saves a temporarily-stored video image of the time.

We use Bhattacharyya distance measurement, which is based on error rate estimation, to measure the distance shown in the following equation (1):

$$
d^{2}(i, j)=\frac{1}{2} \sum_{k=1}^{N} \frac{\left(\mu_{i k}+\mu_{j k}\right)^{2}}{8 \sigma_{i k}+\delta_{k}} \quad \text { Equation (1) }
$$

Here, $N$ is the order of data, $\mu_{i k}$ is $k$-th mean of $i$, and $\sigma_{i k}$ is $k$-th variation concerning variable $i$. Distance estimation is measured only within the overlapping regions of two Gaussian distributions. A Istance range covers 0 to $\infty$, and it represents either complete overlap or no overlap with each daussian distribution. The distance between $\mathrm{p}$ and $\mathrm{q}$ distribution is alculated by the following equation (2):

$$
B_{d t}=\frac{1}{4} \ln \left(\frac{\sigma_{p}}{4}\left(\frac{\sigma_{p}^{2}}{\sigma_{q}^{2}}+\frac{\sigma_{p}^{2}}{\sigma_{q}^{2}}+2\right)\right)+\frac{1}{4}\left(\frac{\left(\mu_{p}-\mu_{q}\right)^{2}}{\sigma_{q}^{2}+\sigma_{q}^{2}}\right) \quad \text { Equation (2) }
$$

Here, $\sigma_{p}$ is the variance of the p-th distribution. $\mu_{p}$ is the mean of the $\mathrm{p}$-th distribution, and $p$ and $q$ are two different distributions. Mixture distance is calculated on a cumulative basis because the combination of Gaussian distributions with a similar weight can be more easily formed.

\section{Experiments}

The software application used in this experiment was built with Visual C++ 2013 in Windows 8 . We use a camera that is designed to be used for iPad applications. The size of the video is optimized to display the shoe rack.

Figure 1 shows the screen which executes a shoes robbery and prevention system. 


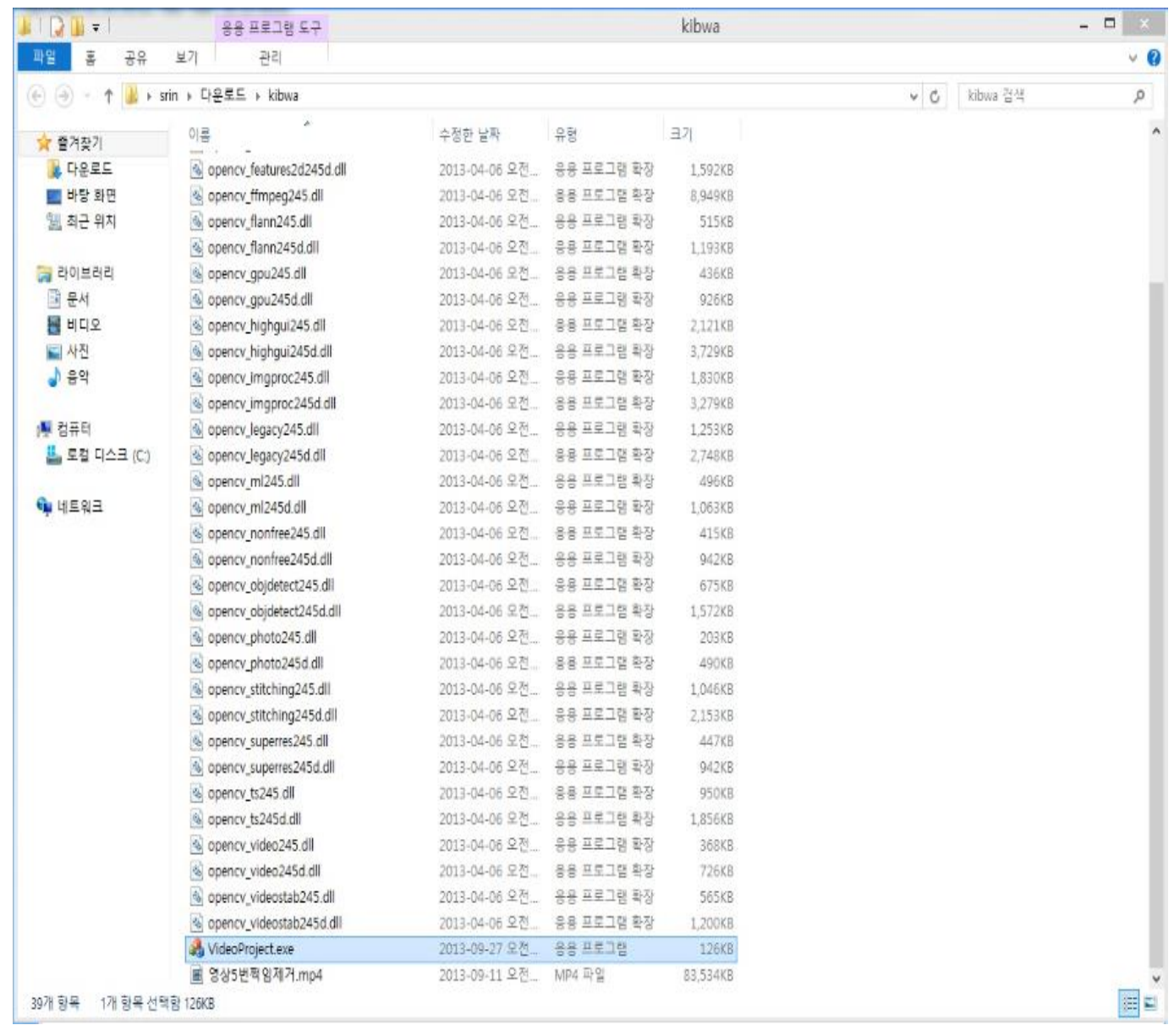

Fqure 1. Shoes Bobbery and Prevention System

Figure 2 shows the screen at executing a program. Each boxes show the actual screen, the mask screen, the shoes location screen and the whole shoe rack screen, etc.

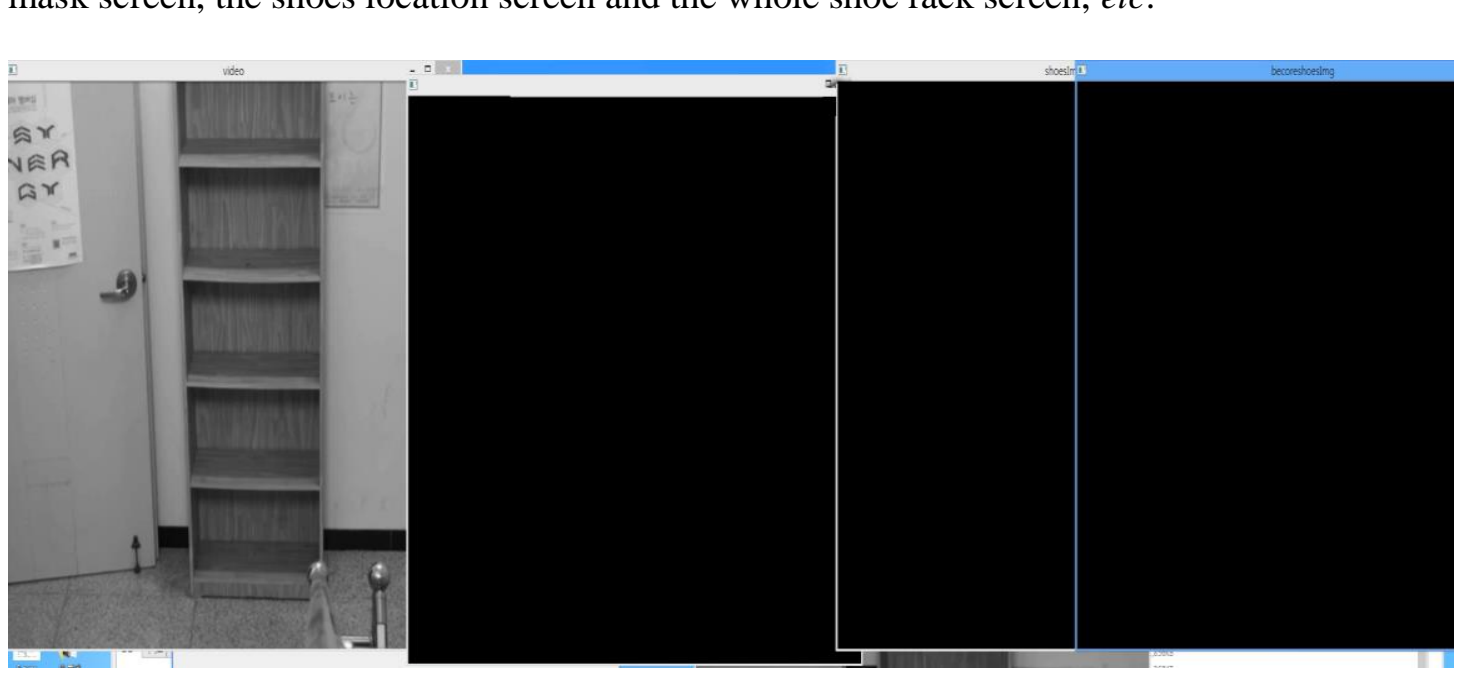

Figure 2. Whole Screen at Executing a Program 
Figure 3 shows the screen when the first person puts in the shoes in the shoe rack.

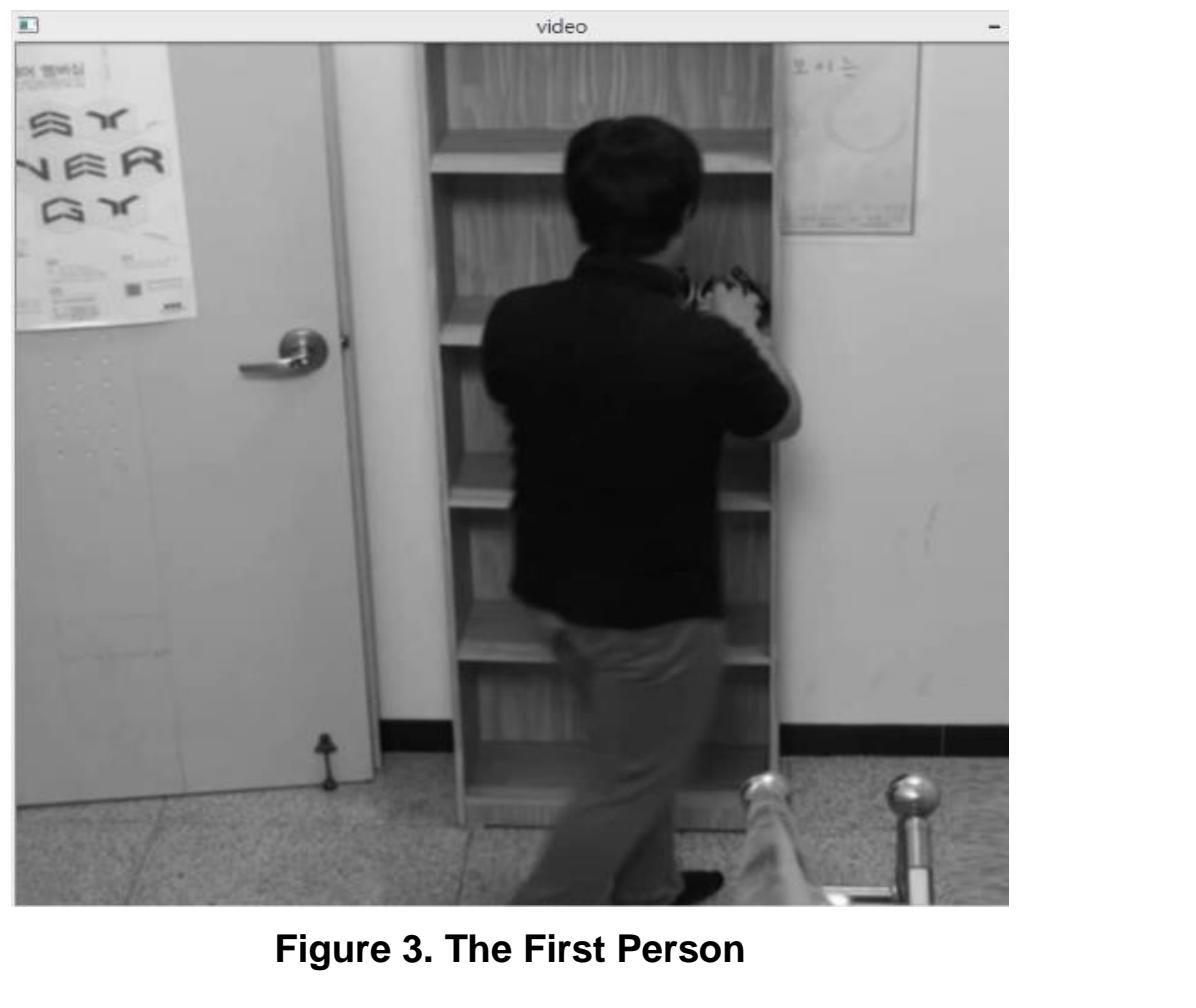

Figure 4 indicates the location of the shoes where the first person puts in.

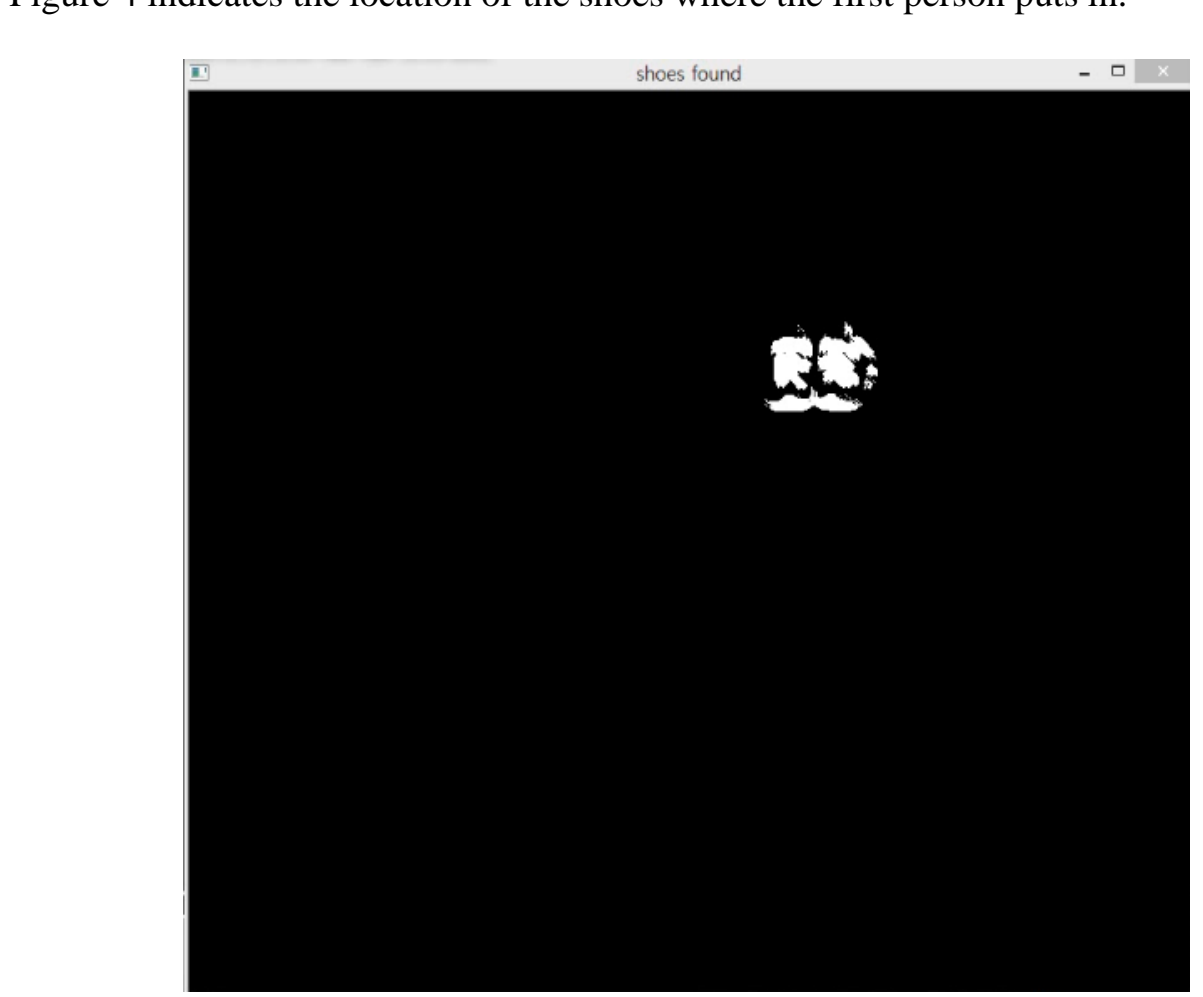

Figure 4. Shoes Location 1 
Figure 5 shows the screen when the second person puts in the shoes in the shoe rack.

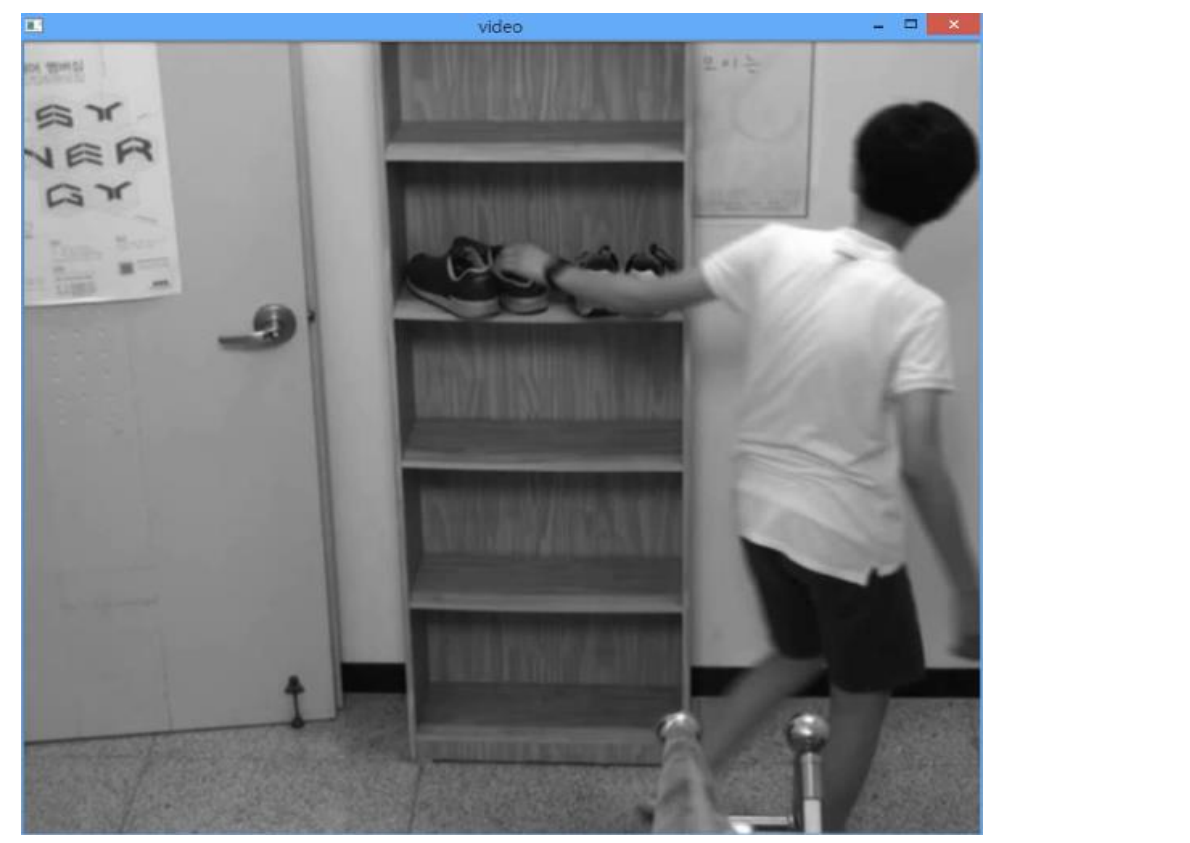

Figure 5. The Second Person

Figure 6 indicates the location of the shoes where the second person puts in.

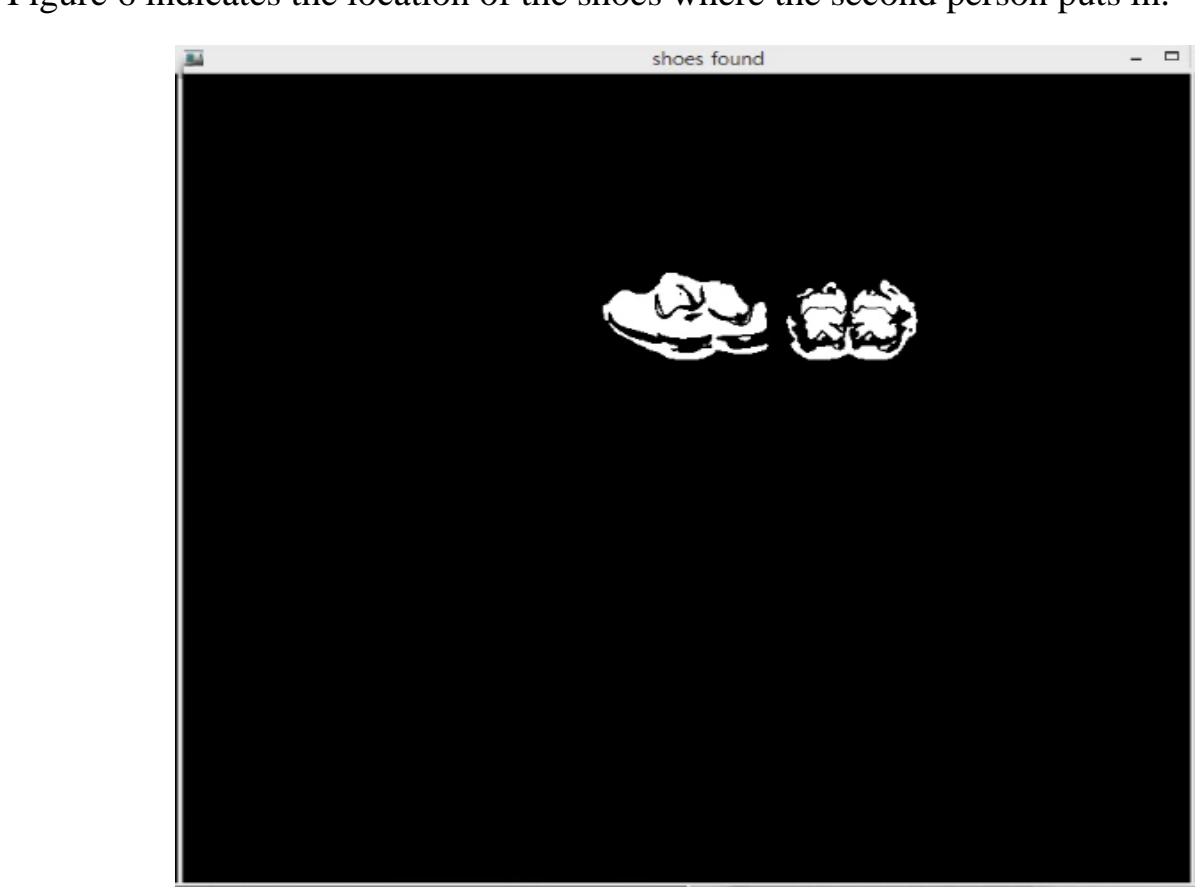

Figure 6. Shoes Location 2

If total four people put in the shoes in the shoe rack, Figure 7 indicates the location of the shoes where the all person puts in. 


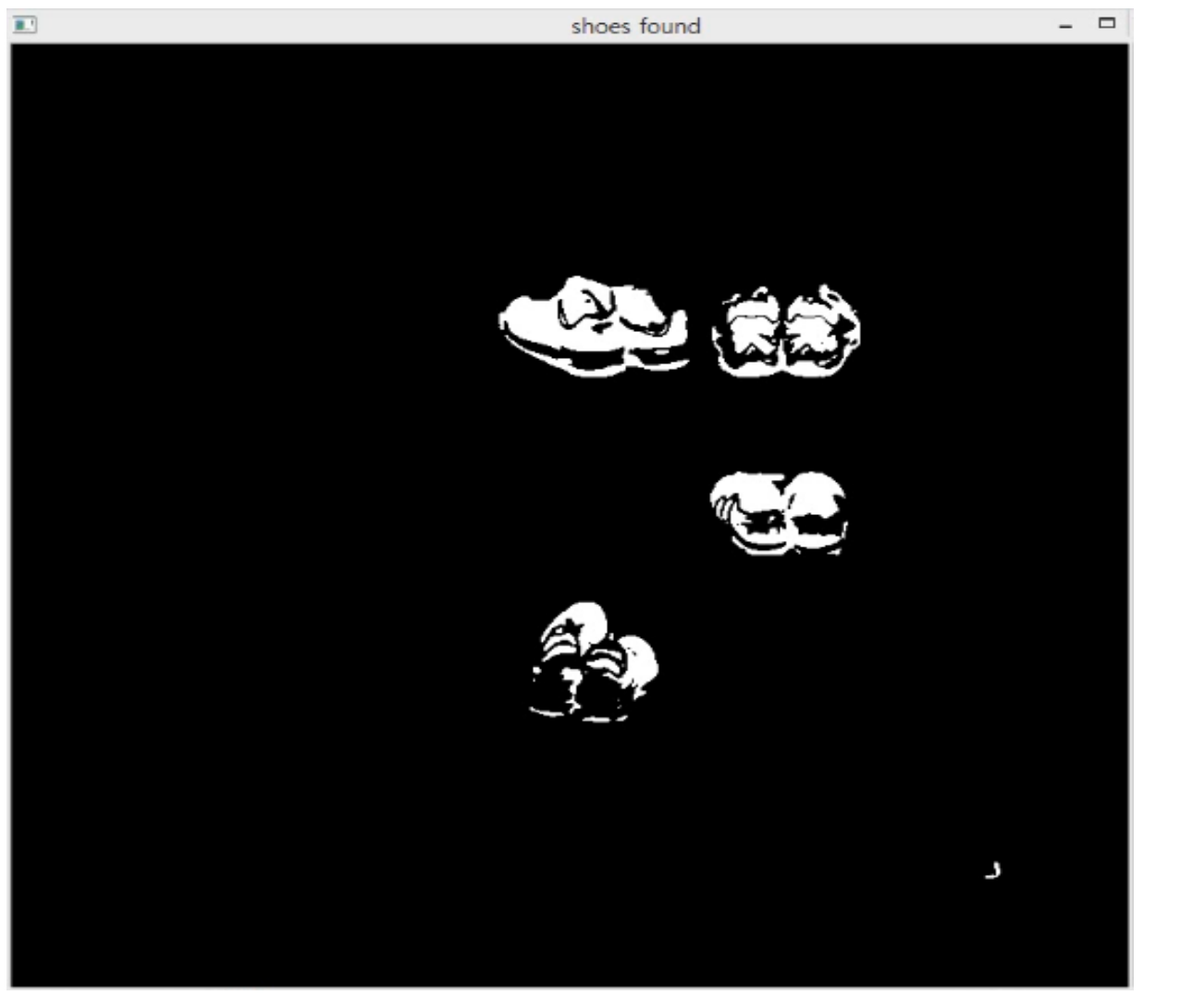

\section{Eigure 7. Tinal Shoes Location}

From above, we will explain the program of each one, now we will explain the execution of whole program. Figure 8 shows the black and white pixel ratio of a binary image of difference images for the shoes' position and person's shape after a person who comes in first takes off his/her shoes.

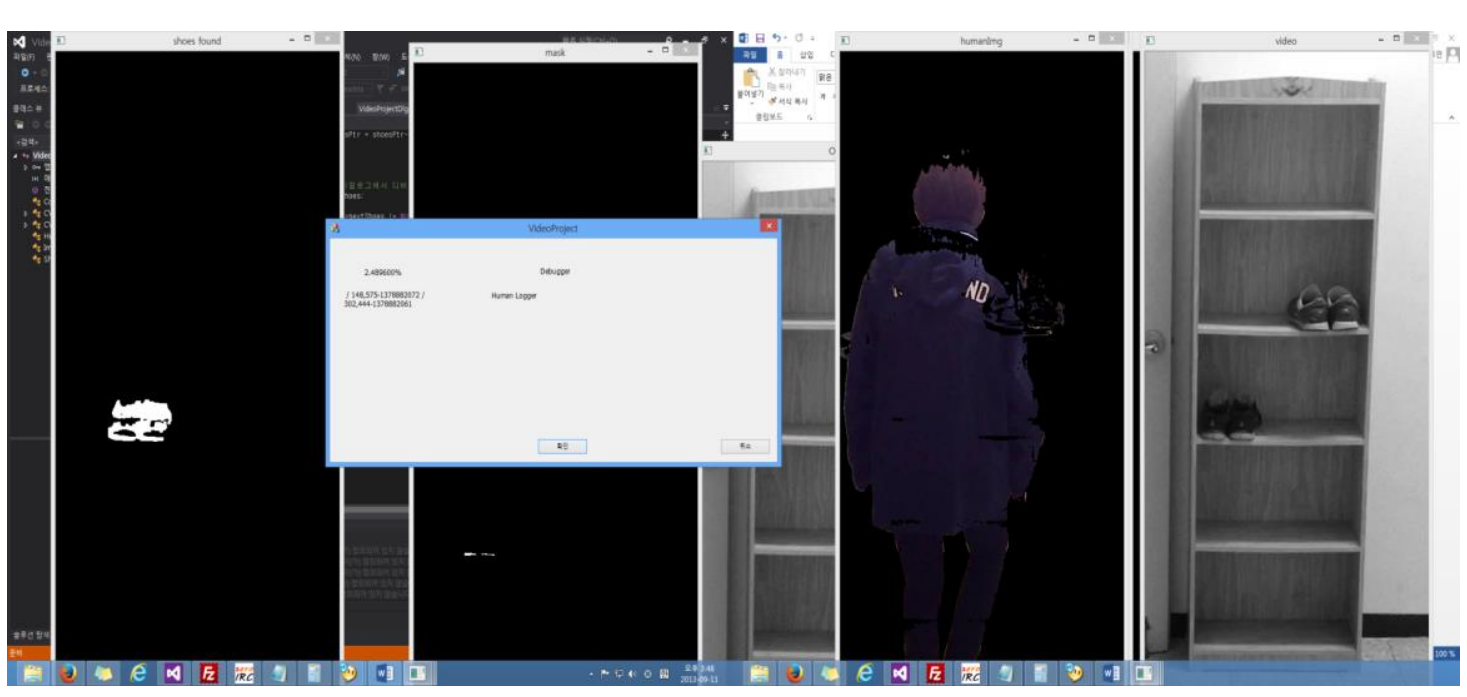

Figure 8. First Person's Position and Difference Image 
Figure 9 shows the black and white pixel ratio of a binary image of difference images for the shoes' position and person's shape after the person who comes in second takes off his/her shoes.

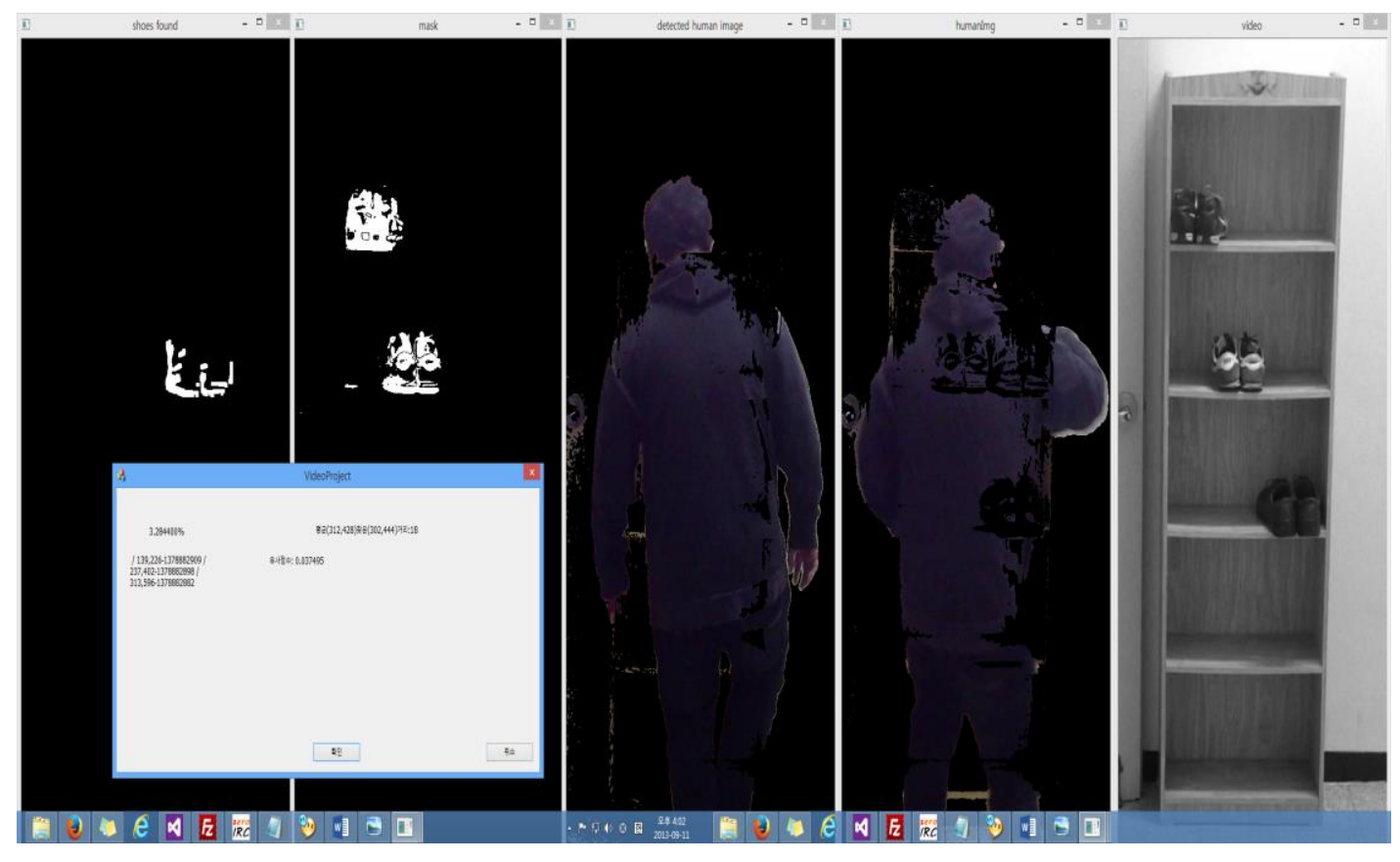

Figure 9. Second Person's Position and Difference Image

Figure 10 shows a case of possible shoo theft. Here, the shoes' position and the black/white color pixel ratio of the binary difference images both show a significant change. Our device will therefore alert the venue owner by either sounding an alarm or an on-screen alert.

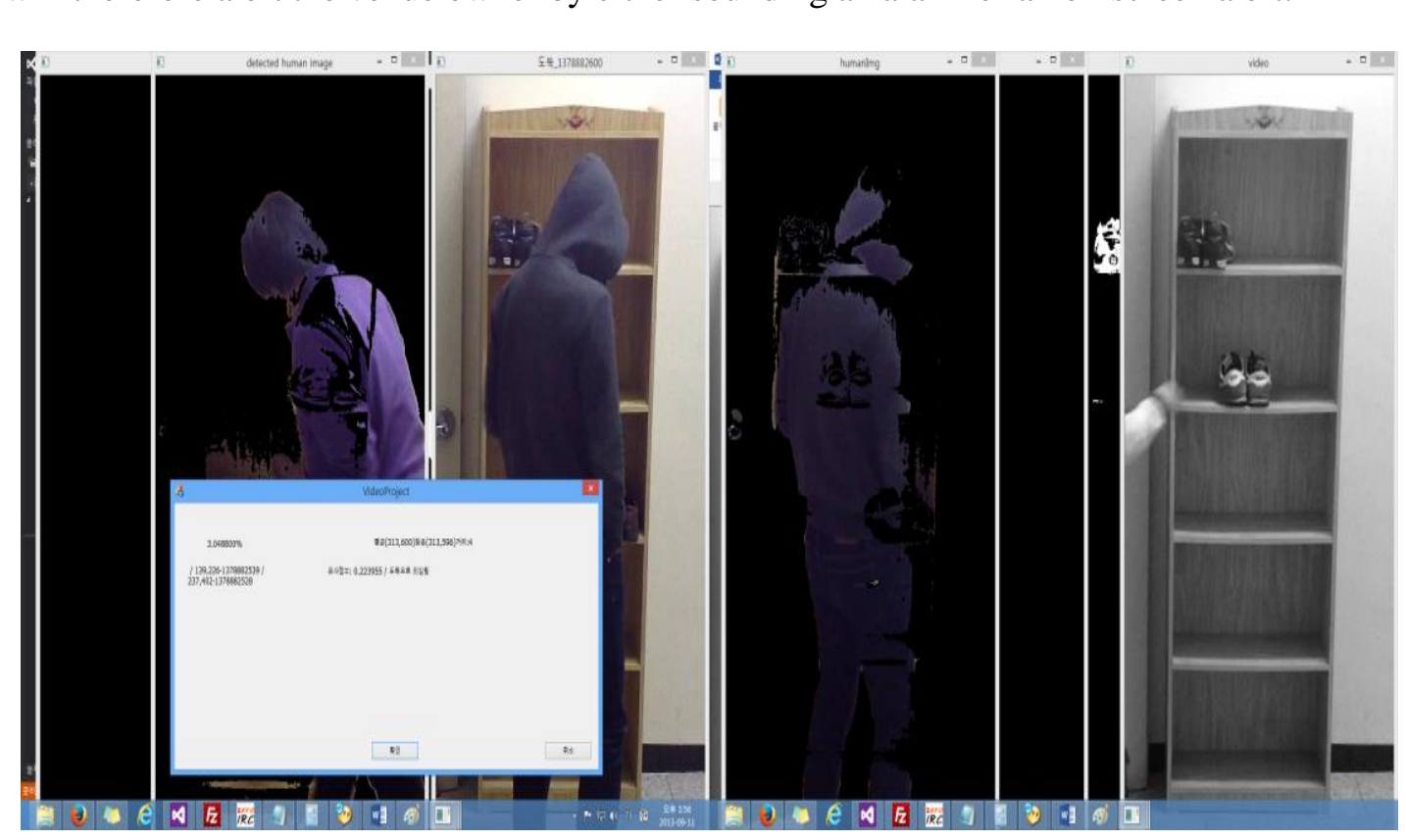

Figure 10. Possible Shoe Theft 
Figure 11 shows the black and white pixel ratio of binary difference images for the shoes' position and person's shape when a person puts his/her shoes back on a shoes rack.

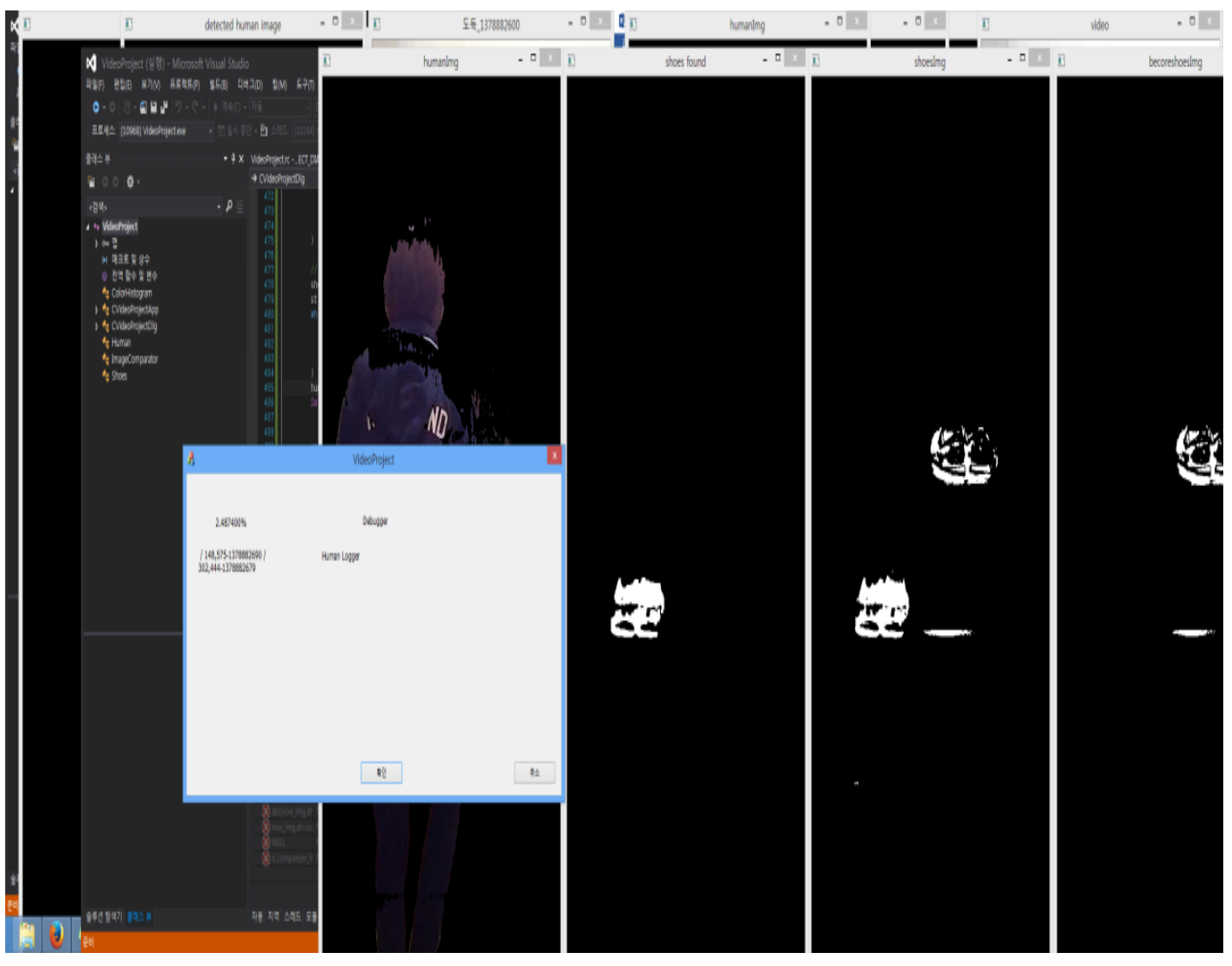

Figure 11. It a Person put Shoes Back to a Rack

This experiments are conducted for fifteen times, and the results of the experiments are shown in the Table 1 .

Table 1. Experiment Results

\begin{tabular}{|c|c|c|}
\hline Experjments & Error $(\mathrm{O}, \mathrm{X})$ & Cause of Error \\
\hline 2 & $\mathrm{X}$ & \\
\hline 3 & $\mathrm{X}$ & $\begin{array}{c}\text { The object (person) wears } \\
\text { more clothes or takes off } \\
\text { clothes }\end{array}$ \\
\hline 4 & $\mathrm{O}$ & \\
\hline 5 & $\mathrm{X}$ & \\
\hline
\end{tabular}




\begin{tabular}{|c|c|c|}
\hline 6 & $X$ & \\
\hline 7 & $X$ & \\
\hline 8 & $\mathrm{O}$ & $\begin{array}{l}\text { The object (person) hold shoes } \\
\text { for a prolonged time and takes } \\
\text { them on the rack }\end{array}$ \\
\hline 9 & $X$ & \\
\hline 10 & $X$ & \\
\hline 11 & $X$ & \\
\hline 12 & $X$ & \\
\hline 13 & $X$ & \\
\hline 14 & & \\
\hline 15 & & \\
\hline
\end{tabular}

The theft or loss of shoes is a commonplace occurrence in Korean society. The high price of a single pair of shoes can hurt people, financially. The objectives of this research are to suggest a detection and prevention system for shoe theft. This research adapts a difference image comparison technique, using bjnary images, pixel rates, time, and a histogram with Bhattacharyya distance measurements. In addition, we assess the originality and feasibility of our research. The use of vided forensics studies supports the basis for recommending our proposed security system. We hope that this research will catalyze society to function in a more morally upright and equitable way. Today, the social fabric is increasingly fraught. With this research, we hope to introduce a positive way for people to go about their day-to-day lives without having to worry about whether their shoes will be stolen or, indeed, whether they should steatsome shoes.

\section{References}

[1] Y.-S. Seo, W.-G. Kim and C.-J. Hwang, "A Study on Digital Image Forensic Marking against Print-andCapture," The Journal of Korea Institute of Communications and Information Sciences, vol. 33, no. 12, (2008), pp. 418-426

[2] K. Seo, K. Lim and S. Lee, "Detecting Similar Files for Digital Forensic Investigation," The Journal of Korean Institute of Information Technology, vol. 7, no. 2, (2009), pp. 182-190

[3] J. W. Shin, "A Study on Digital Forensic Human Training Method," Journal of the Korea Institute of Information and Communication Engineering, vol. 18, no. 4, (2014), pp. 779-789.

[4] H. J. Zhang, A. Kankanhalli and S. W. Smoliar, "Automatic Partitioning of Full-motion Video", Multimedia Systems, vol. 1, no. 1, (1993), pp. 10-28.

[5] Y. Tonomura, "Video handling based on structured information for hypermedia systems, in: Proc. ACM Int. Conf. Multimedia Information Systems, (1991), pp. 333-344

[6] A. Nagasaka and Y. Tanaka, "Automatic Video Indexing and Full-Video Search for Object Appearances", in Visual Database Systems II, Knuth, E., Wegner, L., Editors, Elsevier Science Publishers, (1992), pp. 113-127. 
[7] H. Ueda, T. Miyatake and S. Yoshizawa, "IMPACT: An Interactive Natural-motion-picture Dedicated Multimedia Authoring System", in proceedings of CHI, 1991 ACM, (1991), pp. 343-350, New York.

[8] Kang, S.-J. Cho, Y. Sung In, K. Sungjoo, H. Yo, "Multi-histogram based scene change detection for frame rate up-conversion," 2013 IEEE International Conference on Consumer Electronics (ICCE), (2013). pp. 332333

[9] M. G. Amin and F. Ahmad, "Change detection analysis of humans moving behind walls," IEEE Trans. Aerosp. Electronic Syst., In Press. (2008).

[10] N. I. Radwan, N. M. Salem and M. I. El Adawy, "Histogram Correlation for Video Scene Change Detection," Advances in Intelligent and Soft Computing, vol. 166, (2012), pp. 765-773.

[11] H. Park, H. Lee and S. Sull, "Adaptive parallax control based on 3D scene change detection," 19th IEEE International Conference on Image Processing (ICIP), (2012). pp. 1589 - 1592

[12] J. Lee, S.-J. Kim and C. S. Lee, "Effective Scene Change Detection by Using Statistical Analysis of Optical Flows,“" Applied Mathematics \& Information Sciences, vol. 6, no. 1, (2012), pp. 177-183

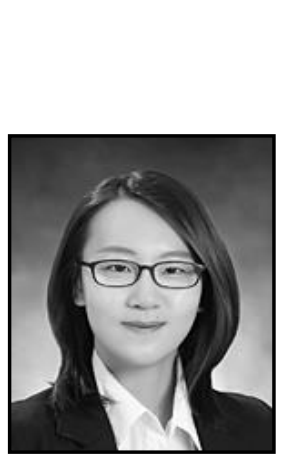

\section{Authors}

Hee_Ae Kin, she is an undergraduate student of the Dept. of Computer Information Engineering of Kunsan N National University, Kunsan, Korea

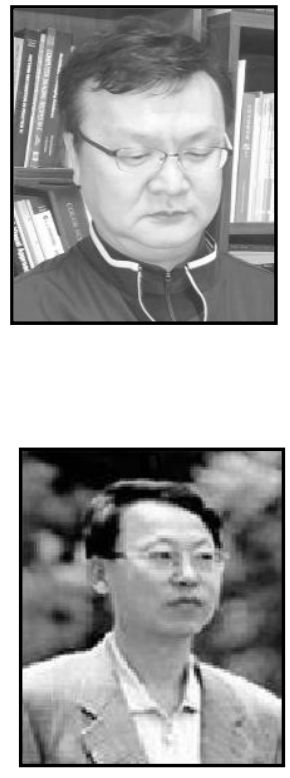

Seong-Yoon Shin, he received his M.S. and Ph.D degrees from the Dept. of Computer Information Engineering of Kunsan National University (Kunsan., Koreá, in 1997 and 2003, respectively. From 2006 to the present, he has been a professor in the same department. His research interests include image processing, computer vision, and virtual reality.

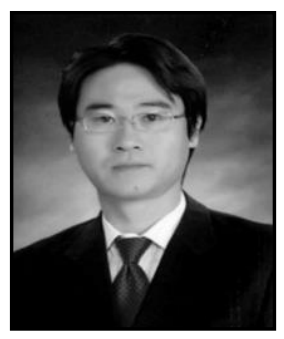

Kwang-Seong Shin, he received his M.S. from the Dept. of Computer Engineering of Chonbuk National University, Ph. D. degree from the Dept. of Computer Information Engineering of Kunsan National University, Kunsan, Korea, in 2005 and 2014, respectively He has worked in the SonIT corp. from 1999 to present. His research interests include image processing, computer vision, and image forensic.. 


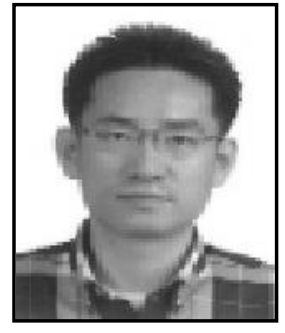

Jong-Chan Lee, he received the M.S. and Ph.D. degrees in computer science and engineering from Soongsil University, Korea, in 1996 and 2000 respectively. From 2000 to 2005 he was a senior member of engineering staff in Mobile Telecommunication Research Laboratory, Electronics and Telecommunications Research Institute (ETRI). He has worked in the Department of Computer Information Engineering, Kunsan National University as a professor. His current research interests are in the areas of mobile multimedia networks.

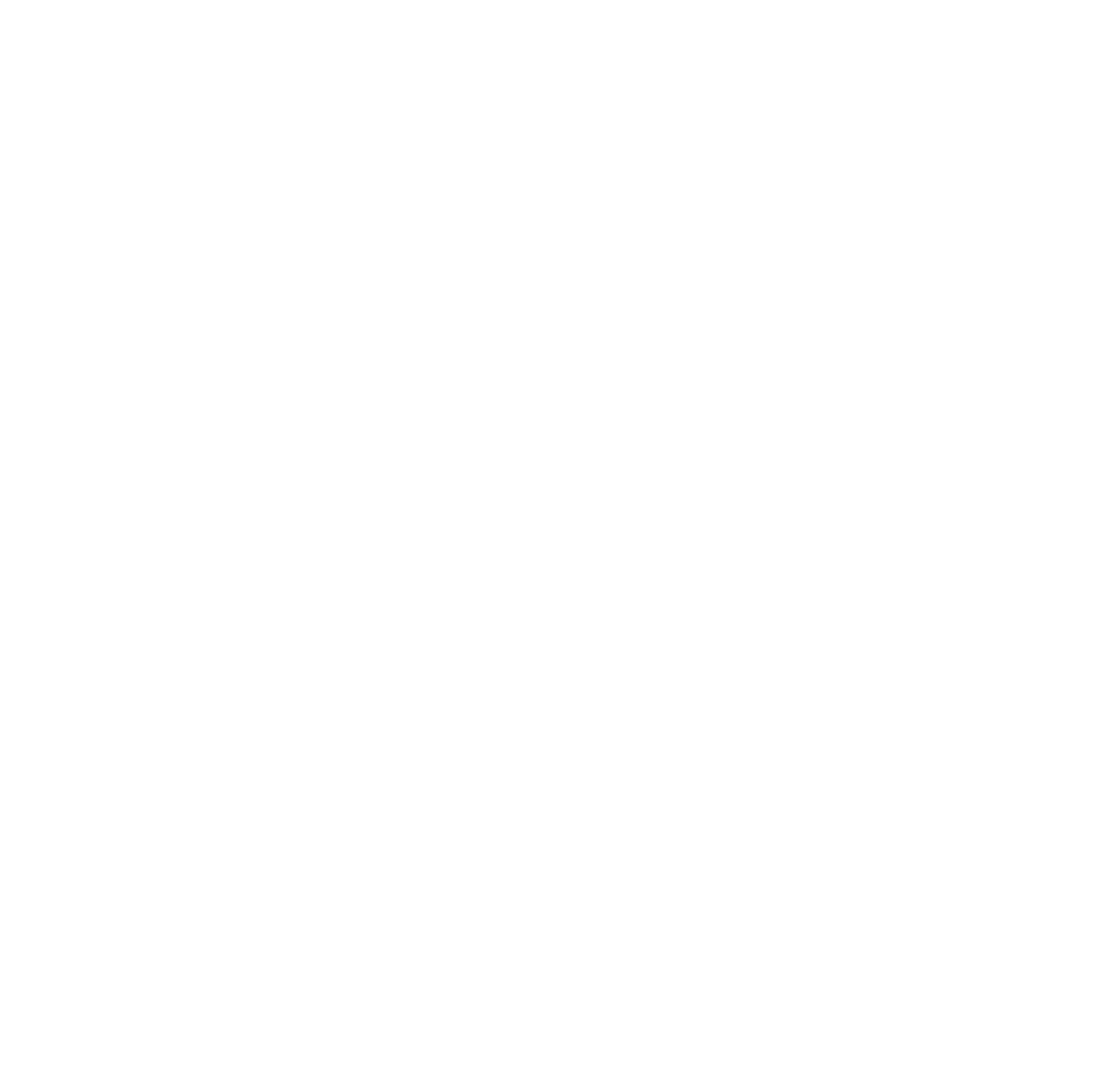


International Journal of Multimedia and Ubiquitous Engineering Vol. 9, No. 10 (2014)

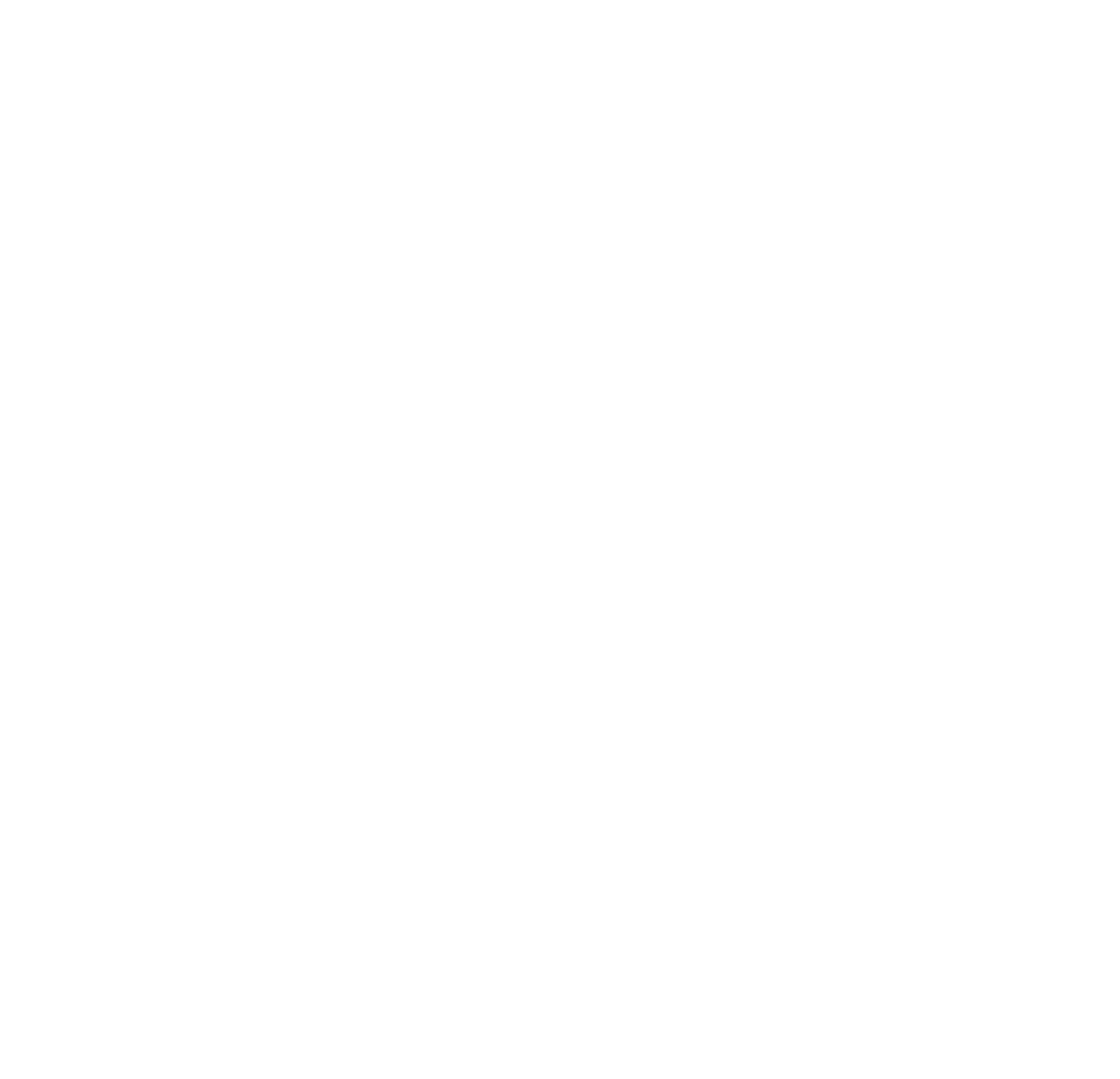

